\title{
A SCRUM AGILE INTEGRATED DEVELOPMENT FRAMEWORK
}

\author{
H. Thiele ${ }^{1, 凶}$, S. Weber ${ }^{2}$, J. Reichwein ${ }^{3}$, J. A. Bartolo ${ }^{4}$, Y. Tchana ${ }^{5}$, L. Jimenez $^{6}$ \\ and J. C. Borg ${ }^{4}$ \\ ${ }^{1}$ Paderborn University, Germany, ${ }^{2}$ Bundeswehr University Munich, Germany, ${ }^{3}$ Technische Universität \\ Darmstadt, Germany, ${ }^{4}$ University of Malta, Malta, ${ }^{5}$ University of Technology of Troyes, France, ${ }^{6}$ Université de \\ Technologie de Belfort-Montbéliard, France \\ $\triangle$ henrik.thiele@hni.upb.de
}

\begin{abstract}
With design methodologies, as Integrated Product Development, industry is continuously looking to improve their product development processes. Staying ahead concurrence forces them to deliver new and more complex products in shorter time. When it comes to fast delivery and requirement changes, product development can be inspired by agile methods. Although the application is difficult, the idea to implement these methods for development of products other than software comes out. To ease its implementation, this paper proposes to use IPD as a framework for agile product development.
\end{abstract}

Keywords: integrated product development, agility, agile-stage-gate hybrid, design methods, design education

\section{Introduction}

In recent years, the product development process has been influenced by diverse drivers. Examples of these are the need for reduced development cycle-time, the market uncertainties (Cooper, 2019) and variations in requirements. Increasing complexity and shorter time-to-market heavily influence the New Product Development (NPD) of mechanical and mechatronic products (Pahl et al., 2007). To meet these challenges, a need exists to develop methods for industrial practices to respond to these challenges (Gräßler et al., 2018).

Different and well established industry based methodologies in NPD have proven useful (Albers et al., 2016), but most are not focused on the generation of artefacts as a development of a minimum viable product. Agile product development methods like scrum, with its roots in software engineering, focus on this aspect (Beck, 2001) and therefore seem complimentary for an industry which faces increasingly shorter time-to-market cycles. The agile mind-set has also been transferred to other aspects of NPD (Gräßler et al., 2017). Even though agile methods face problems for implementation in industry, the need to adopt agile methods in the development of physical products is becoming prevalent (Schmidt et al., 2019). There has been some attention to hybrid methodologies, combining agile methods with conventional approaches in industry as well as in research (Ahmed-Kristensen and Faria, 2018; Conforto and Amaral, 2016; Cooper, 2016).

To cater for this need and to facilitate the implementation of agile product development, this paper presents the background and concept for a hybrid framework for mechatronic hardware development. It combines the advantages of Scrum (Rubin, 2012) as the agile segment to the known 
aspects of traditional methods from the Integrated Product Development (IPD) approach proposed by Olsson (Olsson, 1985). The industry need for a framework as the one presented in this article has been established by a market survey conducted with development engineers from large companies and original equipment manufacturers (OEMs) for mechatronic products. Finally, the framework was applied to the proposed hypothetical development task for the production of a lower limb prosthesis, which was carried out in the context of the IPD summer school conducted in two segments in 2019.

\section{The Scrum agile integrated development model (Scrum AID)}

This section introduces agile product development together with different traditional methods for product development. The determined research gap will be highlighted, and the proposed framework of this paper developed and delimited against the current best practice.

\subsection{State of the art}

As a variety of different NPD methods exist, a broad overview considering different methods and specific facets is undertaken to enable the reader to better follow the delineation of the research gap and the proposed operational framework.

\subsubsection{Agile product development}

Agile development stems from the field of software development (Beck, 2001). As of late, it gained increasing importance not only in software but also in the hardware producing industry. Reasons for this trend are the high expectations regarding the benefits of working agile (Schmidt et al., 2019). Unlike traditional development approaches like VDI 2206, VDI 2221 or Stage-Gate, agile development is able "to react, and adopt to expected and unexpected changes within a dynamic environment constantly and quickly; and to use those changes (if possible) as an advantage." (Böhmer et al., 2015). These changes originate from the uncertainty resulting from a lack of complete knowledge and can be attributed as a negative risk inducing factor or a positive and one that creates opportunities (Atzberger et al., 2019).

Agile development handles this VUCA environment with its incremental and iterative nature. VUCA stands for volatility, uncertainty, complexity, and ambiguity of the environment. In order to cope with this harsh environment several frameworks for agile software development, such as Scrum, Extreme Programming or Kanban, have been developed. Implementing these frameworks in hardware development is limited by the so-called constraints of physicality (Montero et al., 2019; Schmidt et al., 2017). These constraints would be defined for example with the time to market for physical products being usually, significantly higher than that for software. Dealing with those restrictions is necessary to adapt existing frameworks or even to create new ones based on the original Manifesto for Agile Software Development by Beck et al. (Atzberger and Paetzold, 2019).

A framework, whose internal structure can be modified is the Scrum framework (Rubin, 2012). A schematic is depicted in Figure 1. There are different roles in the Scrum framework such as the Product Owner, the Scrum Master and the Scrum or Development Team. The Product Owner is responsible for the overall success of the desired product and defines the requirements. These will be documented in the Product Backlog. On the other hand, the Development Team as an interdisciplinary team has to accomplish the specifications of the Product Owner. As a third role there is the Scrum Master, who oversees the process, acting as a coach on the team and whose main responsibility is to ensure the correct implementation of the Scrum methodology. The Scrum Master is not involved in the actual product development. The key element of Scrum are the Sprints, time slices of work of fixed duration, in which a potentially shippable outcome should be delivered (Rubin, 2012). This outcome is considered as one product increment. Sprints are first planned and work packages determined (selected from the Sprint Backlog), reviewed to assess the increment attained and whether or not a new iteration is needed. Finally, it is reflected upon in order to successfully start the next sprint. During sprints, daily meetings are held to track the development status for the specified requirements. 


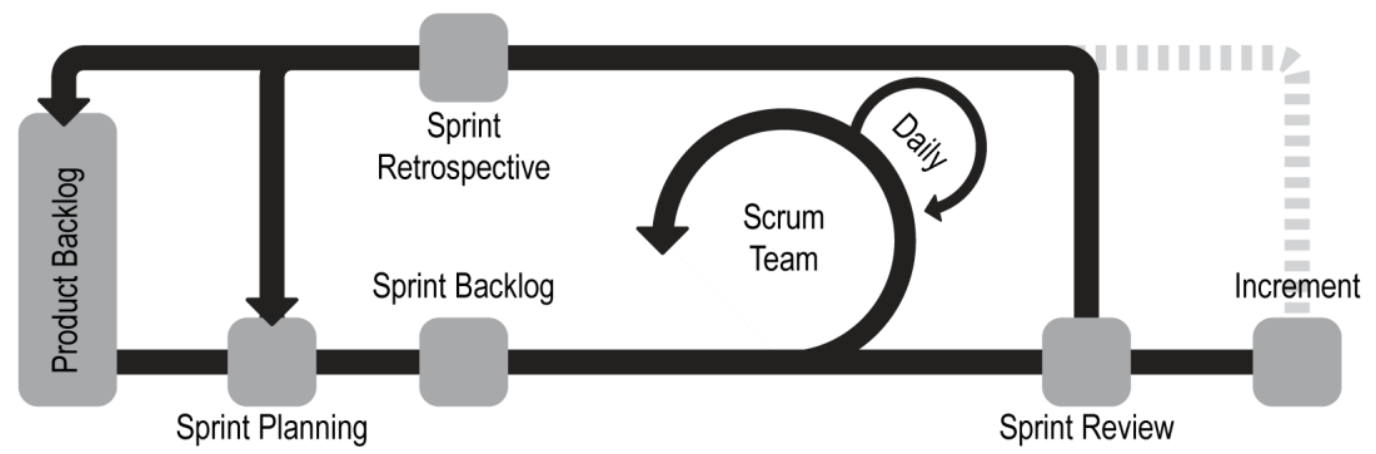

Figure 1. Scrum framework adapted from Scrum.org (2016)

Other alternative approaches are Agile-Stage-Gate Hybrids. Frameworks based on this idea see the agile component as a project planning methodology inside a Stage-Gate process (Cooper, 2016). According to Cooper, agile frameworks such as Scrum are then used by the development team, which is still coordinated with phases of the Stage-Gate process. Agile-Stage-Gate Hybrids are designed to incorporate beneficial features of agile and traditional frameworks, but as currently end up with too much bureaucracy (Sommer et al., 2015).

\subsubsection{Product development and approaches}

Emanating from different communities, various design models and methods are available to product development engineers, to help reduce design iterations, improve integration between different development teams, reduce time to market and improve the overall structure of the development process. The subsequent models have been chosen based on a study by Albers (2016).

\section{V-Model (VDI 2206)}

The V-Model, also known as "Verification and Validation model", links validation and verification phases to each development stage. The first V-Model was adopted from software to mechatronic engineering. In the V-Model, systems to be designed are divided in three levels: system design, subsystem design and part design. At each design stage, validation, verification and integration procedures are concurrently defining the system, subsystem, or part, to ensure that all requirements (user, technical, functional) are adhered to. This reduces the resulting iterations during product development and supports the solution of interdisciplinary tasks by the integration of all domains. (VDI, 2004)

\section{VDI 2221}

The VDI 2221 is a guideline for the development of technical systems using a systemic approach. In the VDI 2221, a design problem is defined, together with each process step in solving the design problem. Each working step is linked to a relative work package and its validation process. If the task is completed and validated, the procedure can continue to the next work task, otherwise new iterations have to be undertaken. In this model, seven fundamental working steps are defined: from the problem definition, to the design of the entire product through the research of technical solutions. (VDI, 1993)

\section{Integrated Product Engineering Model (iPeM)}

iPeM is a generic model that describes product engineering from three different perspectives: a system of objectives describing all explicit targets of a product; a system of objects corresponding and completing the system of objectives and their targets; an operation system that is a socio-technical system including methods, process and resources in order to transform systems of objects into a final product (Albers et al., 2016). In the iPeM, activities are divided into macro and micro activities, where micro activities describe iterative technical problem solving whereas macro activities work at the level of system engineering (Albers, 2010).

\section{Integrated Product Development}

Integrated product development has been introduced in 1981 by Olsson (Olsson, 1985). IPD was a major paradigm change in new Product Development and during the last decades, the advantages of IPD have been discussed. (Ottosson, 2004; Vajna, 2014) 
In IPD's models, different sets of activities from different departments of a company are parallelized in order to enable interdisciplinary work from the beginning of the project (Vajna, 2014), as show in Fig 2. Four sets of activities are considered in the Olsson model: marketing, design, manufacturing and project administration and management. Further models have been developed. Andreasen and Hein (1987) proposed the same model without project management activities. Meerkamm's approach focuses on time, cost and quality improvement through organization, technique, methodology and human capital analysis (Ehrlenspiel and Meerkamm, 2013). Vajna (2014) proposed a human centred process model combining Olsson and Meerkamm approaches, integrating product lifecycle management, sustainable and economic product development.

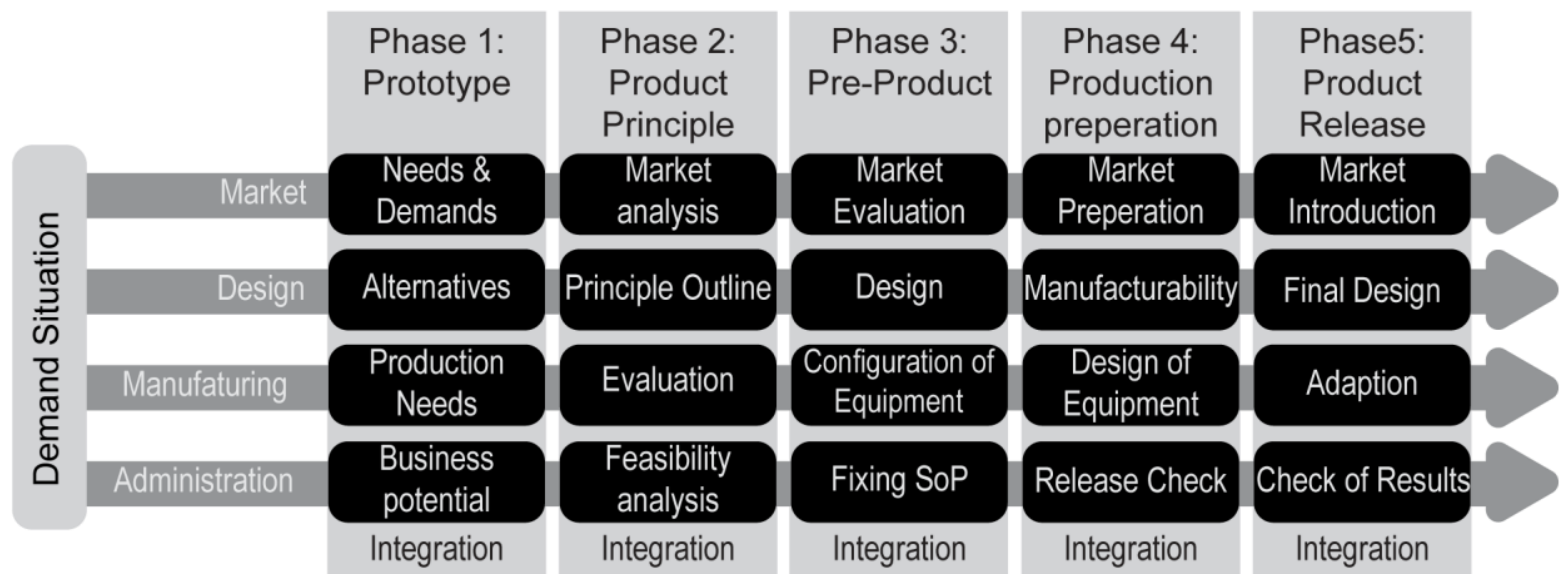

Figure 2. IPD model by Olsson (1985)

\subsection{Research gap}

As shown in the previous section, various approaches to product development exist and are well established in different areas. The implementation of a specific model depends on different aspects, wherein one aspect is to follow an overall trend. A current trend is to implement agile methods such as scrum for the development of physical products. Advantages of agile methods include the fast delivery of artefacts and the possibility to react to requirement changes. The potential is opposed by difficulties in the implementation of agile methods. The implementation phase itself is met with problems as the group work and structure differs from known employed methods. (Atzberger et al., 2019)

Hybrid Stage-Gate models provide a mix of both sides as they implement an agile mind-set within a milestone oriented Stage-Gate approach. This provides a more familiar environment to the development engineer however a clear structure for implementation in hardware development is not available. Moreover, the advantages of state of the art development methods for mechatronic systems, such as concurrent engineering teamwork specifications are neglected. A practical problem of hybrid approaches is the structured cooperation between the different participating disciplines to avoid unnecessary iterations (Luedeke et al., 2018). This aspect will be addressed through a clear division of roles in the proposed framework.

The research question proposed by the authors of this paper considers: How agile product development can be supported by established engineering design frameworks?

The presented research follows the Research Type 3 of the Design Research Methodology (Blessing and Chakrabarti, 2009). For a Descriptive Study I, a literature review was done, to evaluate different methods on the development of mechatronic systems. Based on the evaluation, the IPD Model by Olsson, was selected and altered to serve as a basic framework. Within the agile methods, scrum was selected, and an agile framework for the development of mechatronic systems is proposed (cf. 2.4). Lastly, through the implementation of the framework within a case study (c.f. 3) and a survey among industrial practitioners (cf. 2.3), an initial Descriptive Study II was performed. 


\subsection{The need for the presented framework}

An industry wide survey was conducted to support the need for a hybrid framework as the one presented in this paper. The survey was sent to engineers in the development department of large companies and original equipment manufacturers. The number of participants was limited to nine.

Some of the companies are leading in the automotive sector and develop hardware or combined softand hardware products. Almost $80 \%$ of the engineers surveyed have already worked agile with Scrum as a framework. The second most mentioned framework was Kanban. All participants, who previously worked agile, had trouble implementing it in their companies. Common challenges in the implementation were conflicts in the hierarchy of the companies and conflicts with non-agile structures. Figure 3 depicts, that all those questioned in the survey had heard about Scrum and Kanban, only 56\% showed an awareness for Stage-Gate processes and even less had heard about the IPD model by Olsson (22\%) and the one by Andreasen and Hein (33\%).

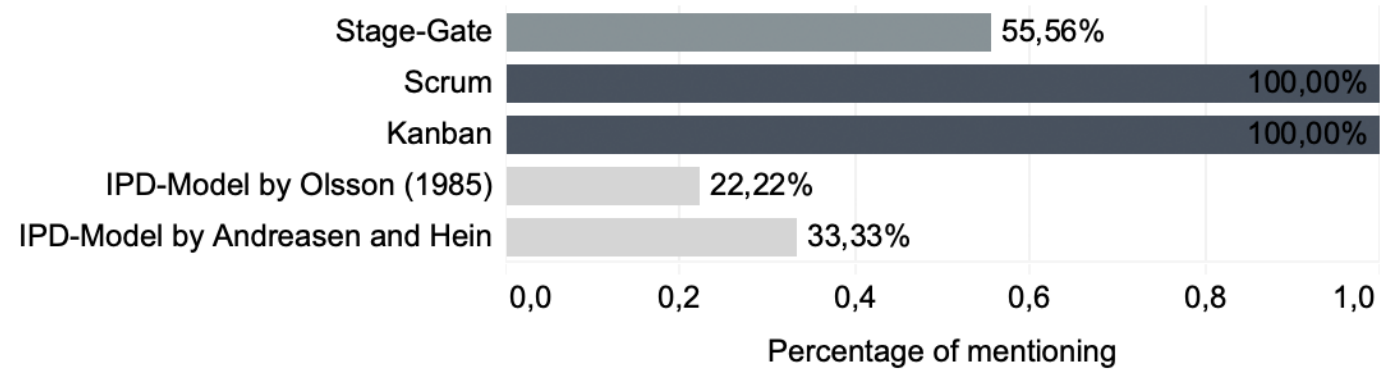

Figure 3. Awareness of the various product development frameworks as derived in the survey

The mean value of a six-point Likert-Scale on participants' opinions on several statements on Scrum and Stage-Gate is shown in Figure 4. It appears that Stage-Gate is much easier to understand by management and team members than Scrum. In addition, it is also clear, that it is hard to react to changes during development with a Stage-Gate process. Opposed to that, agile frameworks like Scrum are commonly known for their possibility to quickly react on changes and using them as a benefit, if possible. This shows that a combination of Stage-Gate with Scrum is promising.
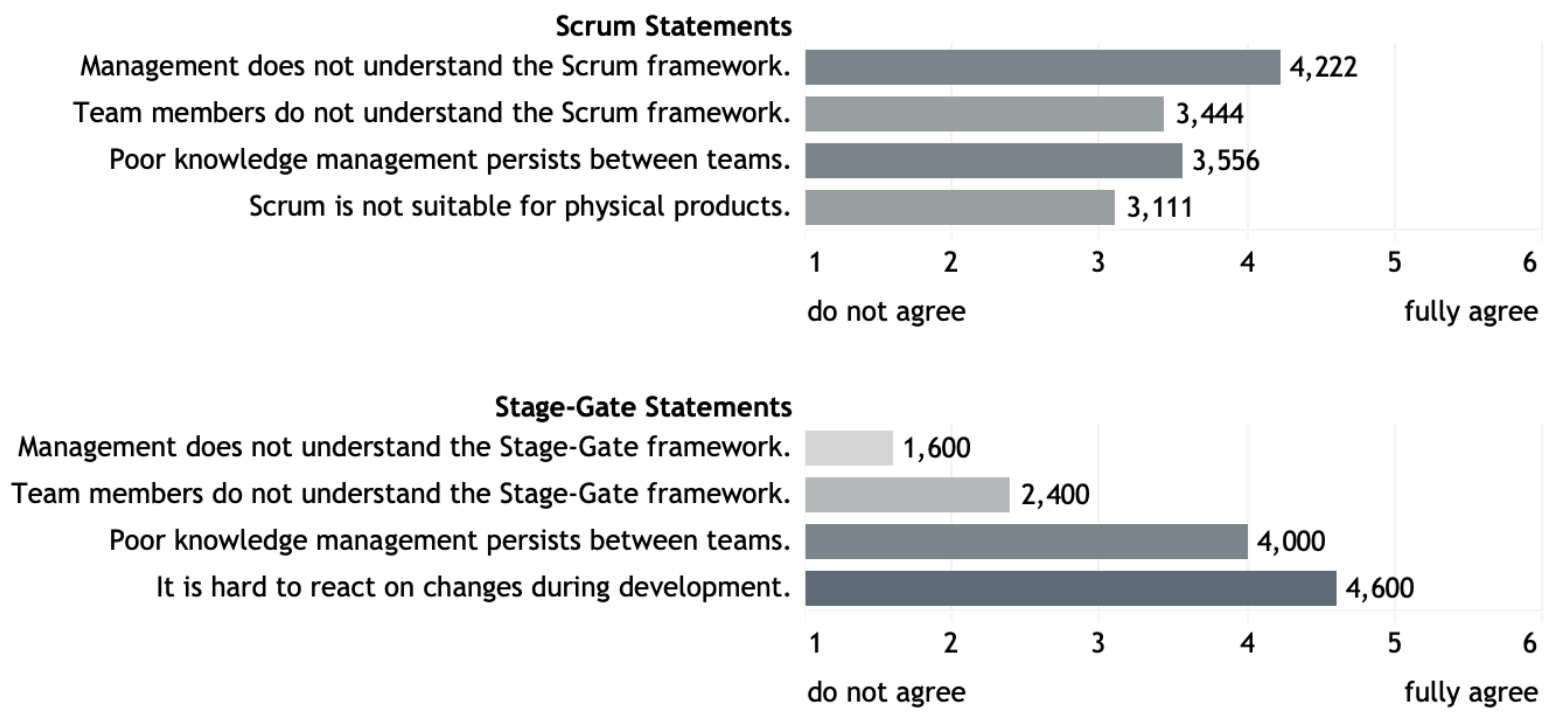

Figure 4. Arithmetic mean values of the survey on framework statements

The questionnaire also showed that the physical constraints in the development of mechatronic products do not affect the product development as much as expected. In addition to the statements of the current problems Scrum and Stage-Gate are facing, the survey asked about pertinent aspects in product development. The most highly rated aspect is the need for daily or weekly meetings with a mean value of 5.3 out of 6 , as shown in Figure 5. The other two aspects are the necessity of a clear 
structure regarding the teams in a company and the possibility to create prototypes fast. Both are rated in average with 3.8 out of 6 .

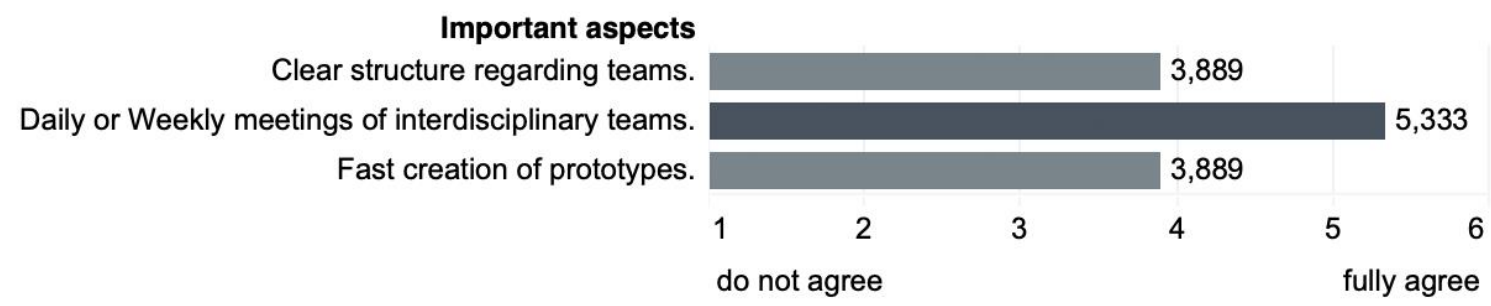

Figure 5. Important aspects during product development according to survey

The results of the survey show, that current agile frameworks do not fulfil the needs of industrial practitioners. Therefore, a need for a new framework can be assumed. In addition, aspects as the clear structure of teams or the ease to understand a framework have been requested by engineers. The framework described in this article aims to combine all beneficial aspects of both sides. Moreover, the assumption taken during the development of the proposed framework, are taken up well by the industrial practitioners and show that the overall direction to be correct.

In order to check the scientific validity and appropriateness, the framework was presented to and reviewed by four professors from universities around Europe, who have deep knowledge in technical product development. The presentation was held at the International Summer School on Integrated Product Development (IPDISS) 2019 and the overall scientific validity and appropriateness was subsequently assessed and reviewed. Minor changes as of the visual representation were implemented and are part of the proposed framework. Furthermore, the framework was applied in a case study to get a further indication of its validity (c.f. 3).

\subsection{Development of the Scrum AID framework}

All the established approaches to product development presented in the state of the art have a different focus and therefore strengths and weaknesses in different fields of application. Table 1 shows an overview of the most used methods for product development and compares them with one another. The results originate partly from the literature (c.f. 2.1) and partly from the survey conducted (c.f. 2.3).

Table 1. Delimitation matrix of established approaches to product development

\begin{tabular}{|l|c|c|c|c|c|c|c|}
\hline & VDI 2221 & iPeM & Stage-Gate & VDI 2206 & IPD & Scrum & Scrum AID \\
\hline Easy to understand/implement & + & 0 & ++ & 0 & + & 0 & + \\
\hline Change of requirements possible & - & - & -- & - & 0 & ++ & ++ \\
\hline Known in industry & ++ & 0 & + & ++ & + & + & $/$ \\
\hline Collaborative team structure & 0 & + & 0 & ++ & ++ & ++ & ++ \\
\hline Clear structure & ++ & + & ++ & + & ++ & - & + \\
\hline
\end{tabular}

It can be seen that the methods commonly used in mechanical engineering have similar weaknesses, whereas the scrum has a different focus. This paper therefore presents a hybrid framework consisting of agile approaches originating from software development and Integrated Product Development, which is often used in mechanical engineering. This so-called Scrum Agile Integrated Development framework (Scrum AID) strives for combining the strengths of both to overcome the above-mentioned deficiencies (c.f. Table 1).

The IPD approach suggests a holistic view, which organizes product development by simultaneous working teams that have different specializations. This kind of organization is well known in product 
development and will be adopted for the Scrum AID approach. Hence, the five phases of the Olsson model Prototype, Product principle, Pre-Product, Production preparation, and Product release are taken as the superordinate structure. This helps to clearly define the intended outcomes of each sprint. As indicated in section 2.1 there are several models for IPD. The Scrum AID relies on the model from Olsson because of the visibly separated stages of the product development process and the separation into four teams with different roles. During the single sprints in the agile scrum procedure, there are two necessary roles: The Scrum team, which is working on the product itself and the Scrum Master who is supporting the Scrum team regarding the scrum procedure.

In contrast there are four different roles in IPD model of Olsson (administration, marketing, design, and manufacturing). The latter three, marketing, design and manufacturing fit well into the agile approach. They are considered together as the Scrum Team and work in parallel on the product, each in their area of expertise, but dependent on the results of the other teams. Consequently, there must be an exchange of knowledge and results, which is organized through daily meetings that are obligatory in the agile Scrum framework. In contrast to these three roles the project administration and management as referred to in the Olsson IPD model acts as the Scrum Master, which supports the other teams with organizational and methodical support during the execution of the sprints.

The Scrum Master is also advising the product development team in all aspects considering the Scrum procedure and is preparing, organizing and leading the daily meetings. Certainly, the work of one team is dependent on the work of other teams. For example, the manufacturing team can only prepare tools for manufacturing if the development team delivers a geometry for the component. Therefore, a crucial task of the Scrum Master is to mediate between the other teams and to organize the exchange of results.

A critical aspect in the agile approach especially for hardware development is the division of workload into tasks manageable during the period of one sprint. To support this subdivision of the whole product development process into sprints the stages of the IPD model are used as a guideline. Figure 6 shows the sprint $\mathrm{n}$ that corresponds to the $\mathrm{n}^{\text {th }}$ stage in the IPD model. The Scrum AID guides the three teams through the agile hardware development process and ensures that the teams are working at the same level of product completion during one sprint. In addition, the three sub-teams are working in the same phase of the product development process and consequently are able to attain all the necessary information from the other sub-teams without waiting for them to catch up.

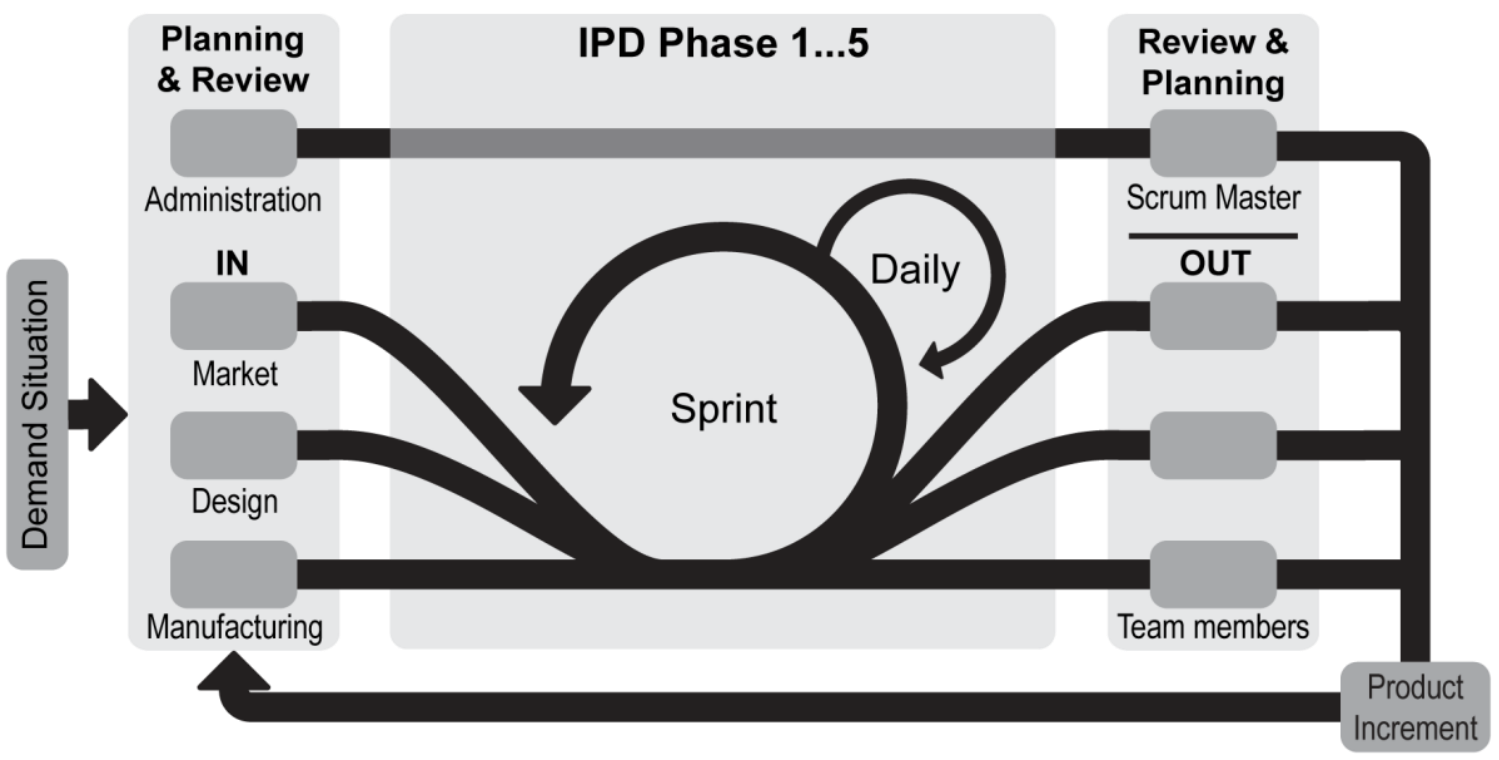

Figure 6. Scrum AID framework

During the sprint planning as in conventional Scrum approaches the division of the workload for the different sprints is organized by the whole team with the support of the scrum master but is mapped out against the five stages of the IPD model. The Scrum AID suggests one sprint for each of the five stages in the different domains, which can of course be adapted to the complexity of the product to be 
developed. After each sprint, there is a sprint review and the team decides if they have effectively finished the current stage making all specified deliverables available and conclusively assess if they may proceed to the next sprint working and initiate work on the next stage.

\section{Case study}

In addition to the survey among industrial practitioners, the developed approach was implemented in a test group as a case study approach to deliver a first hint of evaluation as part of the Descriptive Study I.

The developed approach was implemented in a development project during the International Summer School on Integrated Product Development (IPDISS) 2019. The team consisted of seven members from three different countries who were working remotely from seven different locations over the course of sixteen weeks with the aim to develop a medical device in the field of mobility. The members all have a background in mechanical engineering, working in industry and academia for at least a year.

Each team modelled on Olsson's composition (i.e. market, development and manufacturing), consisted of two members each with administration taking the role of the scrum master. Due to restrictions with regards to timing, the daily stand-up was converted to a weekly stand-up via web meetings. A sprint was timed to four weeks each resulting in the completion of four phases at the end of the project.

The market research carried out by the team was spurred on by World Health Organization estimation that about 30 million people require prosthetic limbs, braces or mobility devices, but only $20 \%$ have access. Therefore, a prosthetic was chosen as the product to develop. The requirements in the third world also pose a difficulty for the availability of skilled professionals to fit the prosthetic. The team developed a volume generation software that could work on the reinterpretation of 2D imagery taken of limb stumps which would be translated into 3D printed silicon artefact, improving the modelling and fitting of the prosthetic limb. This item was identified as the most critical component for prosthetic limb fitting, as a bad fit will result in an unpleasant and painful wear experience. Limb sockets are custom made for the client to ensure best fit and wear ability.

The development therefore relied strongly on the inter team exchange during the weekly stand-up. Especially the pricing and cost calculation was identified as the biggest challenge. The projected development costs of around $€ 200 \mathrm{~K}$ with an annual $€ 100 \mathrm{~K}$ in development and maintenance costs could be returned through a licensing subscription based on a take up a minimal of 100 industrial application users. Through an iterative manner, the costs per unit were brought down to $25 \%$ percent of the original pricing. The feedback on manufacturability and pricing by manufacturing and marketing respectively, were used as an input for design changes for the development team and the feedback proved to be crucial for the development of the final product.

Overall, the presented product concept was perceived well by the professors, guiding the Summer School. This initially provides a degree of proof the IPD framework to be chosen right as a framework for the hybrid stage-gate process. Additionally, using the targets of each phase within the Olsson model as milestones, was evaluated as useful by the group. The milestones gave a clear structure as of which task has to be fulfilled until the next sprint. This supported the fast generation of a prototype and artefacts during the development of the product.

This further supports the choice for the Olsson IPD model. The case study yielded preliminary proof for the correct chosen framework. In particular, the team structure proofed to be beneficial for the process as well as in the attainment of milestones, providing a familiar environment for the team members. As the case study is delimited to a certain degree, additional studies have to be performed.

\section{Conclusion and future work}

Current best practice highlights different New Product Development methods. On one hand design models are used to structure the product development process. The method implementation can be improved upon when used in the development of complex products. Difficulties faced when applying design models and methods are due to the dynamic environment in which complex products are developed. On the other hand, agile methods employed in software development facilitate the solving of issues linked to changes. Hence the necessity to develop new agile methods for development of products other than software. 
In this paper, the authors outline a new framework for the development of hardware products with an agile method, using Integrated Product Development as framework. These were selected with the aim of overcoming the disadvantages of both approaches. The disadvantages were identified from the presented survey, which was conducted among participants working with the respective approaches. Subsequently the proposed framework was actively evaluated in a case study and backed by an industry wide survey among practitioners. Both parts of the evaluation show good preliminary results, but further researches are needed to prove the applicability in industry as part of future work. Future research may include a larger sample for the survey and a case study in a company. Moreover, consideration of other models, as for example Andreasen and Hein are worth considering.

\section{Acknowledgement}

The paper was developed as an outcome of the 2019 International Summer School on Integrated Product Development. The authors thank all supervising professors for their honest and purposeful feedback and our industrial partners for the participation in the survey.

\section{References}

Ahmed-Kristensen, S. and Faria, L. (2018), "Hybrid Agile-Planned product development processes: Preparing the manufacturing sector for industry 4.0 ".

Albers, A. (2010), "Five Hypotheses about Engineering Processes and their Consequences", in: Proceedings of the TMCE 2010. Presented at the TMCE, Ancona, Italy.

Albers, A. et al. (2016), "IPeM-Integrated Product Engineering Model in Context of Product Generation Engineering”, in: Procedia CIRP. Presented at the 26th CIRP Design Conference, Stockholm, Sweden, pp. 100-105. https://doi.org/10.5445/IR/1000060192

Andreasen, M. and Hein, L. (1987), Integrated Product Development, Springer.

Atzberger, A. et al. (2019), "Evolution of the Hype around Agile Hardware Development", Presented at the 2019 IEEE International Conference on Engineering, Technology and Innovation (ICE/ITMC). https://doi.org/10.1109/ICE.2019.8792637

Atzberger, A. and Paetzold, K. (2019), "Current Challenges of Agile Hardware Development: What are Still the Pain Points Nowadays?", Proceedings of the Design Society: International Conference on Engineering Design 1, pp. 2209-2218. https://doi.org/10.1017/dsi.2019.227

Beck, K. (2001), "Manifesto for Agile Software Development”, http://www.agilemanifesto.org/

Blessing, L.T.M. and Chakrabarti, A. (2009), DRM, a Design Research Methodology, Springer-Verlag, London. https://doi.org/10.1007/978-1-84882-587-1

Böhmer, A.I., Beckmann, A. and Lindemann, U. (2015), Open Innovation Ecosystem - Makerspaces within an Agile Innovation Process 11.

Conforto, E.C. and Amaral, D.C. (2016), "Agile project management and stage-gate model-A hybrid framework for technology-based companies”, Journal of Engineering and Technology Management, Vol. 40, pp. 1-14. https://doi.org/10.1016/j.jengtecman.2016.02.003

Cooper, R.G. (2019), "The drivers of success in new-product development", Industrial Marketing Management, Vol. 76, pp. 36-47. https://doi.org/10.1016/j.indmarman.2018.07.005

Cooper, R.G. (2016), "Agile-Stage-Gate Hybrids: The Next Stage for Product Development”, ResearchTechnology Management, Vol. 59, pp. 21-29. https://doi.org/10.1080/08956308.2016.1117317

Ehrlenspiel, K. and Meerkamm, H. (2013), Integrierte Produktentwicklung: Denkabläufe, Methodeneinsatz, Zusammenarbeit, 5th ed. Hanser, München.

Gräßler, I., Hentze, J. and Bruckmann, T. (2018), "V-Models for Interdisciplinary Systems Engineering", Presented at the 15th International Design Conference, pp. 747-756. https://doi.org/10.21278/idc.2018.0333

Gräßler, I., Scholle, P. and Pottebaum, J. (2017), "Integrated Process and Data Model for Agile Strategic Planning", Presented at the 11th International Workshop on Integrated Design Engineering, Magdeburg.

Luedeke, T.F. et al. (2018), "CPM / PDD in the context of Design Thinking and Agile Development of CyberPhysical Systems [WWW Document]", DS 91: Proceedings of NordDesign 2018, Linköping, Sweden, 14th - 17th August 2018. https://www.designsociety.org/publication/40906/CPM+\%2F+PDD+in+the+ context+of+Design+Thinking+and+Agile+Development+of+Cyber-Physical+Systems (accessed 2.12.20).

Montero, J. et al. (2019), "Enhancing the Additive Manufacturing process for spare parts by applying Agile Hardware Development principles", in: Presented at the 2019 IEEE 10th International Conference on Mechanical and Intelligent Manufacturing Technologies (ICMIMT), IEEE, Cape Town, South Africa, pp. 109-116. https://doi.org/10.1109/ICMIMT.2019.8712045

Olsson, F. (1985). "Integrerad Produktutveckling - Arbetsmodel”, Produktutveckling, Sveriges Mekanförbundet 21. 
Ottosson, S. (2004), "Dynamic product development_DPD”, Technovation, Vol. 24, pp. 207-217. https://doi.org/ 10.1016/S0166-4972(02)00077-9

Pahl, G. et al. (2007), Engineering Design. Springer London, London. https://doi.org/10.1007/978-1-84628-319-2

Rubin, K.S. (2012), Essential Scrum: A practical guide to the most popular Agile process, Addison-Wesley.

Schmidt, T.S. et al. (2019), Agile Development of Physical Products - An Empirical Study about Potentials, Transition and Applicability, Universität der Bundeswehr München, Neubiberg.

Schmidt, T.S. et al. (2017), "Agile development and the constraints of physicality: a network theory-based cause-and-effect analysis", in: DS 87-4 Proceedings of the 21st International Conference on Engineering Design (ICED 17) Vol 4: Design Methods and Tools, Vancouver, Canada, 21-25.08.2017, pp. 199-208.

Scrum.org (2016), The Scrum Framework. Available at: scrum.org/resources/scrum-framework-poster (accessed 12.09.2019).

Sommer, A.F. et al. (2015), "Improved Product Development Performance through Agile/Stage-Gate Hybrids: The Next-Generation Stage-Gate Process?”, Research-Technology Management, Vol. 58, pp. 34-45. https://doi.org/10.5437/08956308X5801236

Vajna, S. (Ed.), (2014), Integrated Design Engineering: ein interdisziplinäres Modell für die ganzheitliche Produktentwicklung, Springer Vieweg, Berlin.

VDI, (2004), Guideline 2206: Design methodology for mechatronic systems.

VDI, (1993), Guideline 2221: Systematic approach to the development and design of technical systems and products. 